NBER WORKING PAPER SERIES

\title{
PLATFORM PRICING AT SPORTS CARD CONVENTIONS
}

\author{
Ginger Zhe Jin \\ Marc Rysman \\ Working Paper 17959 \\ http://www.nber.org/papers/w17959
}

\author{
NATIONAL BUREAU OF ECONOMIC RESEARCH \\ 1050 Massachusetts Avenue \\ Cambridge, MA 02138 \\ March 2012
}

We would like to thank University of Maryland and Boston University for financial support. The views expressed herein are those of the authors and do not necessarily reflect the views of the National Bureau of Economic Research.

NBER working papers are circulated for discussion and comment purposes. They have not been peerreviewed or been subject to the review by the NBER Board of Directors that accompanies official NBER publications.

(C) 2012 by Ginger Zhe Jin and Marc Rysman. All rights reserved. Short sections of text, not to exceed two paragraphs, may be quoted without explicit permission provided that full credit, including (C notice, is given to the source. 
Platform Pricing at Sports Card Conventions

Ginger Zhe Jin and Marc Rysman

NBER Working Paper No. 17959

March 2012

JEL No. D4,L1,L8

\begin{abstract}
$\underline{\text { ABSTRACT }}$
We study a new data set of US sports card conventions in order to evaluate the pricing theory of two-sided markets. Conventions are two-sided because organizers must set fees to attract both consumers and dealers. We have detailed information on consumer price, dealer price and, since most conventions are local, the market structure for conventions. We present several findings: first, consumer pricing decreases with competition at any reasonable distance, but pricing to dealers is insensitive to competition and in longer distances even increases with competition. Second, when consumer price is zero (and thus constrained), dealer price decreases more strongly with competition. These results are compatible with existing models of two-sided markets, but are difficult to explain without such models.
\end{abstract}

Ginger Zhe Jin

University of Maryland

Department of Economics

3105 Tydings Hall

College Park, MD 20742-7211

and NBER

jin@econ.umd.edu

Marc Rysman

Department of Economics

Boston University

270 Bay State Road

Boston, MA 02215

mrysman@bu.edu 


\section{Introduction}

The theory of platform competition and two-sided markets is an important recent development in industrial organization (see Armstrong, 2006; Caillaud \& Jullien, 2003; Rochet \& Tirole, 2006; Rysman, 2009; Weyl, 2010; Hagiu \& Wright, 2011), but empirical work has been restricted. While the empirical literature is growing, we argue below that significant gaps remain. In particular, there is little research that focuses on descriptive analysis of data sets with a large number of platforms or in relatively simple settings that are easily interpretable by theory. This paper analyzes sports card conventions in the US, which must attract both buyers and sellers of cards to be successful. We provide a series of empirical results, particularly about the relationship between competition and pricing, and especially competition that we expect affects one side more than the other. Our results would be difficult to rationalize with a one-sided market model, but we argue that our results can be generated by a model based on two-sided markets. The theory of two-sided markets is difficult to test in the sense of falsifiability because it is very flexible. Rather than a direct test, our aim is to provide descriptive results from a market that appears to be two-sided, and discuss our results in the context of theoretical models. Our results go beyond existing theoretical models in that we consider markets with many platforms, whereas existing theoretical research considers markets with at most two. Thus, we evaluate whether intuition obtained from duopoly markets can be extended to more complex market structures.

By definition, two-sided markets involve two (or more) groups of agents in which (1) agents interact through an intermediary and (2) participation or usage of each group affects the utility of the other groups. The intermediating firm is often referred to as a "platform" and each group of agent is referred to as one "side" of the market. The economics of two-sided markets focus on agent's choice of platform and the pricing decisions of possibly competing platforms. ${ }^{1}$ Hagiu \& Wright (2011) argue that this literature would be better termed the study of "multi-sided platforms."

For example, consumers value video game consoles that are served by many game developers, and developers value consoles that attract many consumers. In this case, the console producer is the platform firm, accounting for interactions between game players and game developers. Similarly, a local sports card convention provides a platform for dealers of sports cards (most time acting as sellers) to interact with consumers that visit the convention. Sports card dealers prefer conventions with many consumers (holding competition constant) and consumers prefer conventions with many dealers.

For several reasons, sports card conventions provide an excellent environment to study the theory of two-sided markets, particularly for the relationship between platform pricing and platform competition. First, conventions are two-sided markets. A successful convention requires both buyers and dealers to

\footnotetext{
${ }^{1}$ This focus differentiates the literature on two-sided markets from the literature on network effects. The definition of a two-sided market is very similar to the definition of a market with indirect network effects. However, the literature on network effects tended to focus on technology adoption and network size, rather than the choices of the intermediary (although this distinction is not perfect). For more on network effects, and definitional issues in two-sided markets, see Farrell \& Klemperer (2007), Rochet \& Tirole (2006) and Rysman (2009).
} 
appear at the convention, and a convention organizer must take this into account in setting prices. Second, pricing is very simple and observable. Dealers and consumers pay separate entrance fees only. There are no transaction fees or other complicating issues. We observe these fixed fees in a set of uniformly formatted classified advertisements in a trade magazine. Third, there are a huge number of conventions in the United States, more than two thousand per month at the height of their popularity, which gives us tremendous leverage for econometric estimation, as well as important panel variation in market structure.

In comparison, many two-sided markets (e.g. yellow pages directories, radio, internet search engine) have zero price on one side and therefore restrict platform pricing to the other side only. Contexts in which we see pricing on both sides are often complex. For example, video games consoles are a canonical example of a two-sided market, but the number of important platforms and game developers are less than 25 , contracts are complex and secret, and technological change makes time series variation difficult to interpret.

We highlight several empirical results. We show that consumer pricing responds to increases in competition at any reasonable distance. However, pricing to dealers is more complex: it does not respond to competition within relatively long distances, up to 100 miles. As we consider even longer distances, past 100 miles, dealer prices actually increase in competition. We also distinguish between dealer pricing by conventions that allow free consumer admission and those that charge consumers. We interpret conventions that charge free admission, about half of our data set, to be constrained on the consumer side. We show that conventions with free consumer admission reduce the price to dealers in response to competition, whereas conventions with positive consumer admission do not change dealer prices in response to competition.

We argue that these results are difficult to explain in a one-sided model: why would price increase in or does not respond to competition if the firm has set price and responded negatively to competition for another product in the market? However, these results arise naturally in reasonable models of twosided markets. For instance, if dealers multi-home (i.e. attend multiple conventions) and consumers single-home (i.e. attend a single convention), increased competition between conventions (for instance, exogenously moving them closer together) leads to lower prices for consumers but not for dealers. The result that the single-homing side benefits more from competition than the multi-homing side is a common result and appears in a number of set-ups (see Rochet \& Tirole, 2003; Armstrong, 2006; Gomes, 2011). A second result is that if both sides single-home, and consumer face higher travel costs than dealers, prices fall on the consumer side but can actually increase on the dealer side. Intuitively, since increased competition lowers market shares of consumers, the value of attracting dealers goes down, and the platforms raise price. This result can be inferred from Weyl (2010) and we present a model in the appendix that makes this point explicitly. Thus, a model in which consumers single-home and dealers multi-home when competing conventions are nearby but single-home when they are far apart (i.e. greater than 100 miles) generates the pricing pattern we observe. Our discussions with industry participants 
suggest that this is a reasonable description of dealer behavior.

Armstrong \& Wright (2007) and Gomes (2011) provide an interesting extension to the result that if one side multi-homes, competition does not affect prices on the multi-homing side. If instead we consider the case in which price is constrained on the single-homing side, then increases in competition do cause price to fall on the multi-homing side. This result is consistent with our finding that dealer prices fall in response to competition at conventions with free admission, but do not do so for conventions with positive admission fees when dealers are likely to multi-home (within 100 miles).

Several papers seek to empirically evaluate two-sided markets. Rysman (2004) estimates the positive feedback loop between advertising and entry in the Yellow Pages market and evaluates the welfare effects of entry. Kaiser \& Wright (2006) study pricing in the German magazine market, Argentesi \& Filistrucchi (2007) study market power in the Italian newspaper market, and Fan (2011) studies quality choice in the U.S. newspaper market. Chandra \& Collard-Wexler (2009) study newspaper pricing in the context of mergers. Jeziorski (2011) analyzes merger behavior by U.S. radio stations. Lee (2010), Derdenger (2011) and Corts \& Lederman (2009) evaluate exclusive contracting in the video-game market. Cantillon \& Yin (2008) study tipping in financial exchanges. Genakos \& Valletti (2011) show that lower call termination revenue for cellular phone providers leads to higher fees to subscribers. Rysman (2007) evaluates multi-homing and network effects in payment card usage.

Our paper differs from previous research in that we directly study pricing decisions using a descriptive (or "reduced-form") framework. These empirical results are useful because predictions about pricing choices are, in our view, the major results of the two-sided markets literature so far. By taking a reduced-form approach, we seek to shed light on whether correlations in the data are consistent with the proposed theories. In contrast, most other papers that analyze pricing estimate an explicit theoretical model using structural techniques, which makes it difficult to detect if the model does not hold. A descriptive approach seems natural given that both the theoretical and empirical literatures are at such an early stage. ${ }^{2}$

\section{Industry and Data}

Collecting sports cards and sports memorabilia is a popular pastime in the United States. Sports cards are small cards with a picture of a professional player and the player's statistics. Baseball cards are the most popular. Collectors value cards of top players in top or rookie years, as well as complete sets and well-produced cards. Collectors are often interested in other types of memorabilia, such as game balls, jerseys or player signatures. The popularity of collecting cards can vary a great deal, including seasonally with whether a sport is in season, and regionally with the success of the local team. A major event in

\footnotetext{
${ }^{2}$ A related empirical literature focuses on indirect network effects, such as Gandal, Kende \& Rob (2000), Saloner \& Shepard (1995) and Ackerberg \& Gowrisankaran (2006). Consistent with the theoretical literature on network effects, these papers focus on technology adoption rather than pricing by an intermediary.
} 
our data set is the labor strike in Major League Baseball in 1994, which hurt the popularity of the league and of collecting baseball cards.

Sports card conventions provide short events for dealers and consumers to come together. While a number of dealers establish retail shops, many dealers trade entirely at conventions. A small convention may last one day and consist of 10 tables set up at a mall. The largest conventions have more than 250 tables, last a week, and take over a large convention center in a major city. Convention organizers rent the location, advertise the convention and charge fees to dealers and consumers. Conventions sometimes contract for the appearance of professional athletes who will provide signatures for free. Organizers primarily profit from the entrance fees, although some organizers are also dealers who will trade cards at the convention. Both the organizer and dealer markets are extremely unconcentrated and are characterized by many small participants, many of whom have separate full-time jobs unrelated to sports cards.

Pricing at conventions is very simple. Consumers and dealers pay a fixed fee to the convention organizer. Typically, consumers pay less than $\$ 2$, with about half of the conventions in our data set offering free admission. Dealers pay the "table fee", typically $\$ 25$ to $\$ 100$. The table fee allows the dealer to set up a table at the convention. Prices at multi-day events may be more complicated, with prices varying by day (for instance, weekend prices are typically higher) or with lower per-day fees for admission over multiple days. Also, we observe some discounts from the table fee for purchasing multiple tables. $^{3}$

Our data set is based on the trade magazine Becket Baseball Card Monthly. This magazine provides articles on baseball and collecting, market prices for a huge number of cards, and most importantly for our purpose, listings for sports card conventions (the "Convention Calendar"). Listing is free and, as we understand it, every convention would be sure to place a listing in this magazine. The magazine requires that listed conventions have at least 10 tables, although this does not appear to be binding (see below). Each calendar covers the month of the issue, so the October 1997 issue has listings for all conventions in that October.

Our data set consists of the convention listings from a selection of issues of this magazine. Convention organizers fill out a standard form and listings follow a uniform pattern, which is amenable to computer interpretation. To create our data set, we scanned all of the listings and used an Optimal Character Recognition (OCR) program (in particular ABBYY PDF Transformer 1.0) to convert these scans to text files. Then we wrote computer programs to parse the results into a usable data set. To ensure data quality, we compared the original copy with each parsed listing and corrected errors by hand.

\footnotetext{
${ }^{3}$ In practice, dealers can buy from consumers and dealers can trade with other dealers, as can consumers with other consumers. Hence, the important distinction is not who buys cards and who sells cards but who pays the table fee and who pays the consumer fee. There could be substitution between entering with a table and not doing so. Such substitution could be problematic for our theoretical predictions since it does appear in existing theoretical work, but should bias our results away from finding the differences between the two sides that we show.
} 
Each convention lists the city or town in which it occurs. We match these towns to a list of towns from the U.S. Census and assign the longitude and latitude of the town to the convention. Hence, we assume that each convention is located in the population center of the town in which it occurs. ${ }^{4}$ We drop conventions that do not occur in the continental United States. We dropped some listings that did not provide town names that we could reliably match to a location in the census. Altogether, we have data on 50,450 conventions in 36 months over 9 years.

For each listing, we use the dates of the convention, the town and state, the number of tables, the admission fee for consumers and the table fee for dealers. ${ }^{5}$ For prices, we always took the price for a single day of admission if there were discounts for multi-day admission. We used the simple average of prices if there were different prices for different days. We took the price for a single table if there were discounts for multiple tables.

Our selection of magazines range from April, 1989 to December, 1997, for a total of 36 issues. As the magazines are drawn from a personal collection, it is not a continuous set of magazines. ${ }^{6}$ We purposely stopped collecting data after 1997, which coincides with the popularity of the World Wide Web. There is a significant decline in the number of conventions during the late 1990s which makes our approach difficult since we rely on the presence of competition to create our tests. ${ }^{7}$ Table 1 lists the issues of the magazine in the data set, along with the number of conventions in each issue. Figure 1 graphs this series. There is a peak in activity in the Summer and Fall of 1992 when there are regularly more than 2000 conventions in a month. There is a steady decline afterwards, presumably due to the baseball strike in 1994 and the popularity of the Internet. In 1997, there are less than 1000 conventions per month.

We are interested in oligopoly interactions, so it is useful to get a sense of the number of conventions in any given region. Table 1 provides the mean number of conventions per 3-digit zip code by month for zip codes that have at least one convention. The overall average is 3.15 , and this ranges from 1.90 to 4.35 in months with low and high activity. Not surprisingly, the distribution underlying these means is highly skewed. Table 2 displays the number of 3-digit zip code-months with each count of the number of conventions. For instance, there are 6,886 zip code-months in which we observe only 1 convention in

\footnotetext{
${ }^{4}$ The listings provide addresses which in principle could be used to more accurately identify locations. However, many addresses are descriptive ("VFW Hall" or "Westgate Mall") and therefore are difficult to geocode. Even for the entries that provide a street address, cleaning them would be an enormous task.

${ }^{5}$ We discarded some information: the exact location, the times of day of each convention and the contact name and number. The contact names are potentially very interesting but difficult to clean reliably.

${ }^{6}$ Our collection of magazines is drawn from those we found for sale at several conventions, and some contributions from John List (for which we are very grateful). We made a number of attempts to find missing issues, for instance at public libraries. We believe that our selection of magazines is random.

${ }^{7}$ The impact of the Web on the convention market represents an interesting topic in its own right, as in Goldmanis, Hortascu, Syverson \& Emre (2010) for booksellers and travel agents. Jin \& Kato (2007) present a detailed study on the online and offline trading of sports cards. Here we shy away from the post-Internet months because it would be difficult to determine the channel by which the Web affects conventions. Not only does the Web represent an alternative method for trading cards, the Web represents an alternative leisure activity which substitutes for card collecting altogether.
} 


$\begin{array}{crr}\text { Date } & \text { mean } & \text { count } \\ 1989 \text { Apr. } & 1.90 & 497 \\ \text { Aug. } & 1.80 & 386 \\ 1990 \text { Nov. } & 2.80 & 1276 \\ \text { Dec. } & 2.84 & 1278 \\ 1991 \text { Nov. } & 3.97 & 2206 \\ 1992 \text { Jan. } & 3.90 & 1805 \\ \text { Apr. } & 4.23 & 2477 \\ \text { Jul. } & 4.35 & 2294 \\ \text { Oct. } & 3.99 & 2233 \\ \text { Nov. } & 4.16 & 2294 \\ 1993 \text { Feb. } & 3.57 & 1797 \\ \text { Mar. } & 3.75 & 1950 \\ \text { Apr. } & 3.70 & 2084 \\ \text { Jul. } & 3.64 & 1840 \\ 1994 \text { Feb. } & 3.41 & 1646 \\ \text { May. } & 3.63 & 1827 \\ \text { Jul. } & 3.38 & 1563 \\ \text { Aug. } & 3.32 & 1516\end{array}$

$\begin{array}{crr}\text { Date } & \text { mean } & \text { count } \\ 1994 \text { Oct. } & 3.30 & 1701 \\ 1995 \text { Feb. } & 2.78 & 1250 \\ \text { Apr. } & 2.99 & 1457 \\ \text { May. } & 2.71 & 1196 \\ \text { Aug. } & 2.72 & 1169 \\ \text { Nov. } & 2.97 & 1216 \\ 1996 \text { Feb. } & 2.56 & 1051 \\ \text { Jun. } & 2.69 & 1217 \\ \text { Sep. } & 2.61 & 1098 \\ \text { Oct. } & 2.56 & 918 \\ 1997 \text { Feb. } & 2.39 & 933 \\ \text { Apr. } & 2.48 & 989 \\ \text { May. } & 2.41 & 957 \\ \text { Jun. } & 2.40 & 942 \\ \text { Jul. } & 2.31 & 746 \\ \text { Aug. } & 2.41 & 862 \\ \text { Oct. } & 2.37 & 946 \\ \text { Dec. } & 2.43 & 832\end{array}$

Table 1: Number of conventions and average by 3 digit zip code for each month in data set.

Figure 1: Number of conventions by date.

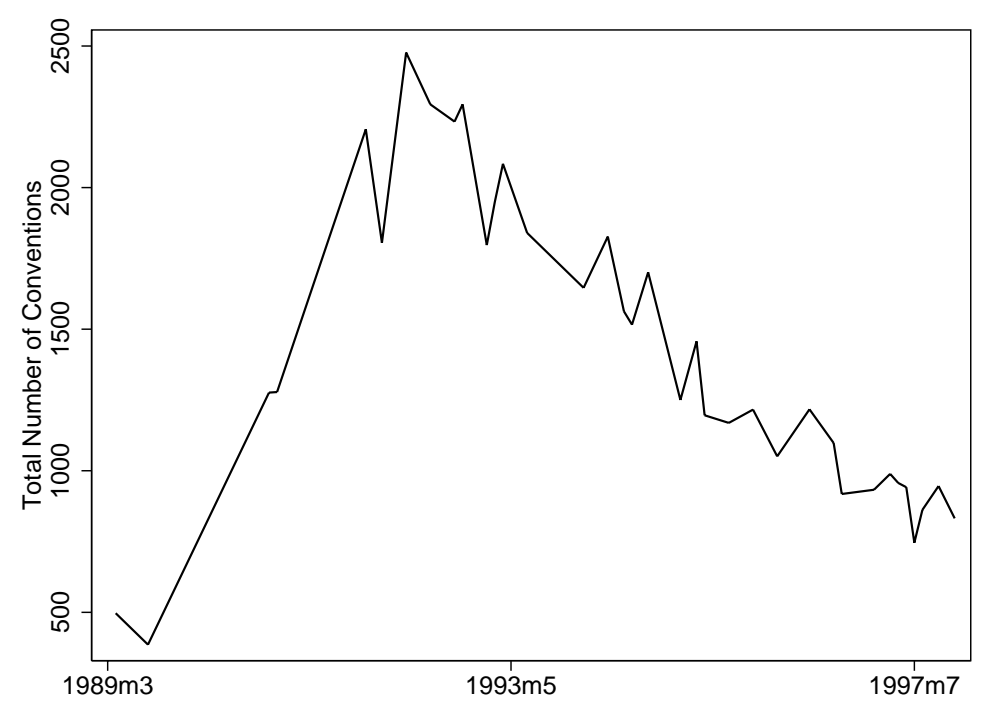


Table 2: Number of conventions per 3-digit zip code.

\begin{tabular}{|c|c|c|c|c|c|c|c|}
\hline Count & Number & Perc. & Cum. Perc. & Count & Number & Perc. & Cum. Perc. \\
\hline 1 & 6,886 & 43.04 & 43.04 & 11 & 135 & 0.84 & 96.1 \\
\hline 2 & 3,285 & 20.53 & 63.57 & 12 & 88 & 0.55 & 96.65 \\
\hline 3 & 1,745 & 10.91 & 74.48 & 13 & 91 & 0.57 & 97.22 \\
\hline 4 & 1,154 & 7.21 & 81.69 & 14 & 65 & 0.41 & 97.62 \\
\hline 5 & 717 & 4.48 & 86.17 & 15 & 52 & 0.33 & 97.95 \\
\hline 6 & 458 & 2.86 & 89.04 & 16 & 49 & 0.31 & 98.26 \\
\hline 7 & 376 & 2.35 & 91.39 & 17 & 46 & 0.29 & 98.54 \\
\hline 8 & 243 & 1.52 & 92.91 & 18 & 23 & 0.14 & 98.69 \\
\hline 9 & 207 & 1.29 & 94.2 & 19 & 25 & 0.16 & 98.84 \\
\hline 10 & 169 & 1.06 & 95.26 & $>19$ & 185 & 1.2 & 100 \\
\hline
\end{tabular}

a month, which represents 43.04 percent of the data. Zip code-months with three or less conventions represent almost $75 \%$ of the data, and 10 or less represents $95 \%$ of the data. There is a tail of observations with a large number of conventions, the maximum being 49 conventions in a 3 digit zip code in a single month.

The number of tables at a convention is an important explanatory variable for price. We treat the number of tables as an exogenous measure of the quality of the convention. Clearly, the quantity of dealers that purchase a table at the convention may be endogenous to the price of a table. However, the "number of tables" listed in the calendar is determined well before the final count of how many dealers will appear. We regard the posted number as "cheap talk" that serves to inform readers of the expected size of the event. Consider that the "number of tables" variable falls disproportionately on multiples of 5 (like 10, 15, 20 etc.), unlike a true measure of quantity. The variable is also highly correlated with other measures of quality, such as the number and quality of athletes that will be available to sign autographs. ${ }^{8}$ Thus, we interpret the number of tables to capture in reduced form both the effect of the number of tables and the effect of other correlated quality variables. As the number of tables is not verified by our data source, organizers could choose it in a misleading way. Our approach assumes the extent of misrepresentation does not vary systematically with competition.

Table 3 describes the distribution of the number of tables. The mean is 41.6 and the median is 35 .

\footnotetext{
${ }^{8}$ We do not observe other measures of quality. However, some conventions take out display advertisements in the calendar section, and from these it is clear that larger conventions offer extra features such as autograph sessions with athletes, door prizes and free raffles.
} 


\begin{tabular}{|cr|r|rr|} 
Perc. & Tables & Perc. & Tables \\
\hline 1 & 10 & & 75 & 50 \\
5 & 15 & & 90 & 70 \\
10 & 20 & & 95 & 90 \\
25 & 25 & & 99 & 160 \\
Median & 35 & & Mean & 41.6 \\
\hline
\end{tabular}

Table 3: Distribution of the number of tables.

\begin{tabular}{|c|c|c|c|}
\hline Perc. & Table Fee & Perc. & Table Fee \\
\hline 1 & 10 & 75 & 50 \\
\hline 5 & 15 & 90 & 80 \\
\hline 10 & 20 & 95 & 102.5 \\
\hline 25 & 25 & 99 & 165 \\
\hline Median & 35 & Mean & 43.7 \\
\hline
\end{tabular}

Table 4: Distribution of table fee

The distribution is approximately log normal. The 99th percentile is 160 . The magazine states that conventions have at least 10 tables to be listed but this does not appear to be binding. A number of conventions list less than 10 tables and the number of conventions listing 10 is not large compared to surrounding numbers. For instance, 589 conventions list 10 tables and 1,502 list 15, and 4,212 list 20. We find missing listings or listing of 0 number of tables at 1,853 observations and drop these in our statistical work.

Most conventions, $77.1 \%$, last only one day. Almost all (98.8\%) last three days or less. Most take place on weekends. In our data, $49 \%$ cover a Saturday, $53.7 \%$ cover a Sunday, and $81 \%$ cover Saturday or Sunday.

The dependent variables in our empirical work are the prices. Table 4 displays the distribution of the table fee. The mean is $\$ 43.7$ and the median is $\$ 35$. The distribution is approximately log normal, with a long tail of expensive conventions. The 99 th percentile is $\$ 165$ but we observe a few with table fees greater than $\$ 1000$.

A striking feature of the distribution of the admission fee is that $52.9 \%$ of conventions feature free admission. A further $29.6 \%$ charge a fee of $\$ 1$. There is little further variation, with much of it falling on multiples of 50 cents. The 95 th percentile is $\$ 2$. These features lead us to model the admission fee as a binary variable so we simply predict whether admission is free or not. With more than $80 \%$ of the observations choosing 0 or 1 , this seems like a decent approximation. Figure 2 graphs the distribution of admission fees in a histogram. 


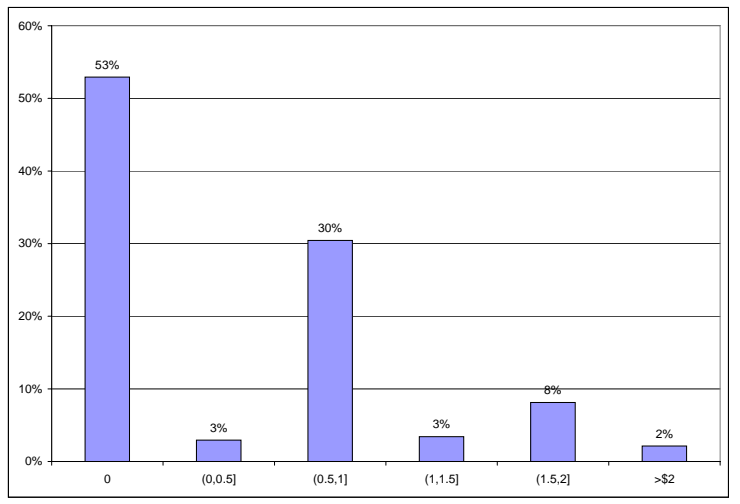

Figure 2: Admission fee distribution

\begin{tabular}{|c|c|c|c|c|c|c|c|c|c|}
\hline \multicolumn{10}{|c|}{ Distance in Miles } \\
\hline & 5 & 10 & 25 & 50 & 75 & 100 & 150 & 200 & \\
\hline \multirow[t]{2}{*}{ Same Day } & 1.24 & 1.44 & 2.5 & 4.27 & 5.93 & 7.77 & 11.87 & 16.84 & 50450 \\
\hline & (0.57) & $(0.88)$ & $(2.54)$ & (4.74) & $(6.40)$ & (7.94) & (11.39) & (15.56) & \\
\hline Within & 1.68 & 2.39 & 5.80 & 11.03 & 15.45 & 20.06 & 30.02 & 42.10 & 38801 \\
\hline 3 Days & (1.12) & (2.11) & (6.84) & $(12.30)$ & (15.70) & (18.62) & $(24.94)$ & $(32.90)$ & \\
\hline
\end{tabular}

Table 5: Average number of competitors by distance

We compute the number of competitors that a convention faces by counting the number of conventions within a given range of time and geographic distance. For example, we calculate the number of conventions on the same day within 25 miles. To do so, we use any competing convention that has at least one day that overlaps with the convention in question. As stated above, we calculate distance based on the latitude and longitude of the relevant towns in the U.S. Census. Table 5 provides the average number of competitors by different distances. Note that when computing the "within three days" variable, we treat the observation as missing for any convention for which we do not have data on conventions within three days. So for instance, a convention on April 30, 1989 would be problematic since we do not have the May, 1989 issue so we cannot count all conventions within three days. Hence, Table 5 displays a lower number of observations for the "within three days" row than the "same day" row. Given that the great majority of conventions appear on the weekends, we interpret "within three days" as essentially meaning "same weekend". Because of these small numbers and the very local nature of the organizing market, we expect organizers to know with some accuracy in advance the number of conventions they will face on any given day. Hence, prices respond to competition although prices and competition are announced publicly at the same time.

A final element of our data set is our contact with card convention organizers. We interviewed several 
convention organizers via e-mail. Their answers were similar and were sufficient to get a sense of how our issues were regarded by industry participants. Our questions were focused on the nature of competition between conventions, as well as competition with other sources of memorabilia. We asked about strategies that organizers used to maintain successful conventions and we were particularly interested in whether consumers and dealers were likely to be attending multiple conventions. The basic results were consistent with how we characterize the theoretical models of the market. Dealers are likely to travel further (have lower travel costs) than consumers. For a dealer, 100 miles was feasible but more than 200 miles of travel was unlikely. Larger dealers might attend multiple conventions in the same weekend, but would probably not be willing to do so if it meant long travel times. Also, our participants regard the Becket magazine as a very reliable data source.

\section{Empirics}

In this section, we present a series of regressions that further explore this data set. In the next section, we interpret the results from the perspective of the theory of two-sided markets.

In addition to considering issues of two-sided markets, we must also address econometric issues of unobserved heterogeneity and omitted variable bias. These issues are important when we consider the relationship between pricing and competition. Demand factors are not entirely observable, and we expect that high unobservable demand will lead both to high prices and to more entry, which creates bias in our estimates. We address this issue by including location fixed effects, where locations are indicated by 3-digit zip codes.

To see how our strategy works, we start with regressions of price on nearby competition. These regressions do not address any issues raised by two-sided markets but rather serve to verify that our fixed effects strategy works appropriately. Results appear in Table 6. In the first two columns, we have results from a linear probability model predicting when admission fees are not zero, as a function of the number of nearby competitors.

We do not include location fixed effects in the first two columns. We do however include time fixed effects, at the level of the month, and controls for the days of the week. ${ }^{9}$ We include time fixed effects and day-of-the-week controls in all specifications in this paper, although we do not report their effects. We include one control variable in all of the regressions: the log of the number of tables. We interpret

\footnotetext{
${ }^{9}$ Our controls for the days of the week consist of dummy variables for each combination of days that appear in our data set more than 500 times. For instance, there is a dummy variable for Saturday-only conventions, one for Sunday-only conventions, and a separate dummy for conventions on both Saturday and Sunday. The full set of dummy variables capture $97 \%$ of the data set. We also include the duration of the convention (1, 2 or 3 days), which serves to better match the remaining $3 \%$ of conventions. We do not report any of these results in the paper. In all regressions, we reduce heterogeneity by dropping conventions that last more than three days, although we still use them for purposes of computing the number of competitors.
} 
this variable as a control for the quality of the convention and, not surprisingly, it is positive and both economically and statistically significant in every specification.

In column 1 of Table 6 , we define competition to be the log of the number of competitors within 25 miles, and in column 2 we use 50 miles. We add one to the number of competitors to address log zero issues. In both cases, we see that competition is positive and statistically significant, as if competition caused higher prices. However, this result appears to be driven by unobserved geographic heterogeneity. In columns 3 and 4 , we include location fixed effects. In this specification, we see that competition has a negative effect on the likelihood of setting a non-zero admission fee and that this effect is significantly different from zero at a confidence level of $1 \%$. Our results are robust to using Chamberlain's conditional logit model (Chamberlain, 1980) to predict the probability of using a positive admission fee with location fixed effects. We conclude from this regression that our measure of competition and our fixed effects strategy addresses the omitted variable problem, at least in part.

We see similar results when we use the log of the table fee as the dependent variable. We use a linear model for the log of the table fee and estimate with linear panel data techniques. In the first two columns of the second panel in Table 6, we present results without location fixed effects. In these cases, the effect of competition on price is estimated to be statistically insignificant, and is very close to zero. However, the next two columns include location fixed effects, and here we see that competition has a negative and statistically significant effect for distances of both 25 and 50 miles. The effect is not large - the elasticity is around -0.02 . But we believe this to be an upper bound due to the positive correlation induced by remaining unobserved heterogeneity. ${ }^{10}$

Note that the number of observations is slightly lower when we use the table fee because the table fee is missing for a number of observations. Restricting the admissions fee regressions to observations in which the table fee is present does not change results. For both admission fee and table fee regressions with fixed effects, some observations are dropped because the dependent variable does not vary within a zip code.

The focus of our interest is on the asymmetric effect of competition on the two sides of the market. To the extent that distance affects consumers and dealers differently, we capture the asymmetry by distinguishing between "near competition" and "far competition." We define near to be those conventions within 25 or 50 miles, and far to be those within 100 or 150 miles, not including near competitors. Again, we require all competitors to overlap in calendar time by at least one day.

We report the results of near and far competition in Table 7. In the first panel, we see that for all definitions of distance, an increase in both near and far competition makes free admission more likely. All effects are significant at $1 \%$ confidence levels.

In the second panel, we see that near competition also drives down table fees, and does so with effects similar to what we found in Table 6 . However, far competition measured within a 100 mile radius has

\footnotetext{
${ }^{10}$ Note that the negative coefficient on dealer prices is not predicted by the theory of two-sided markets, but we show below that it is explained by the conventions that do not charge admission, consistent with theory.
} 


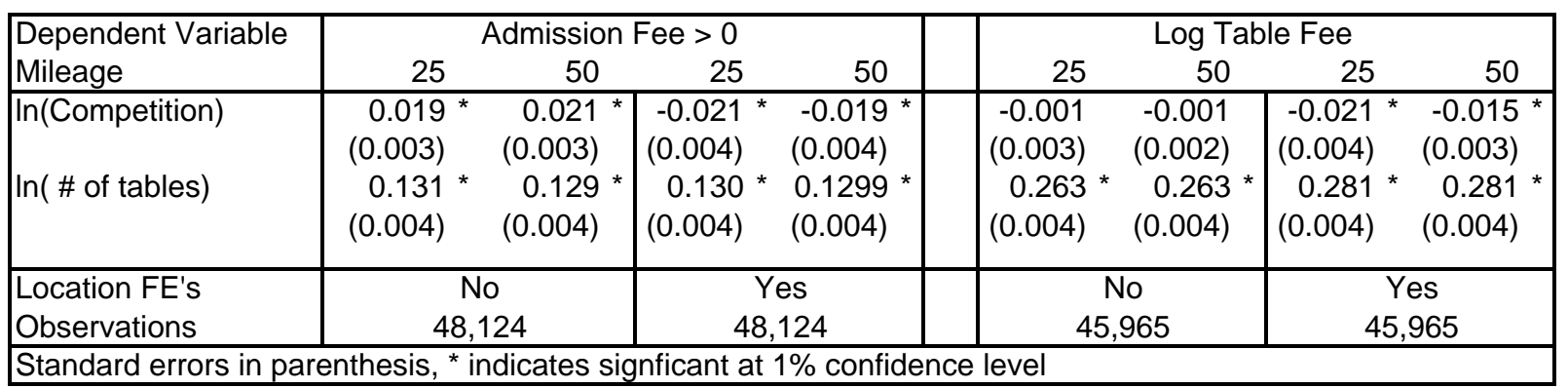

Notes: All columns use linear models. Location fixed effects are 3 digit zip codes. All models include fixed effects for time (monthly) and days-of-the-week the convention covers. Competition is the number of conventions within the "Mileage" number that overlap in the calendar (plus 1 to address log zero).

Table 6: Regressions with and without location fixed effects

no significant effect on table fees, and far competition measured within 150 miles has a positive effect on prices. The key feature of our empirical result is the pairing of the negative coefficient on one side of the market with the zero or positive coefficient on the other side.

Obviously, a positive effect of competition or even a zero effect is hard to explain with standard models. We argue below that it is consistent with a reasonable model of two-sided markets. An alternative explanation for the positive coefficient on far competition is that it is due to endogenous entry, so that unobserved temporal-geographic heterogeneity causes this result. However, this idea is hard to formulate because we include time and location fixed effects and because we find a negative coefficient on nearby competition. While it is plausible that there is heterogeneity that varies over time and space jointly, it must also somehow operate in a wider area more strongly than a local area, and affect the two sides of the market in an asymmetric way. 


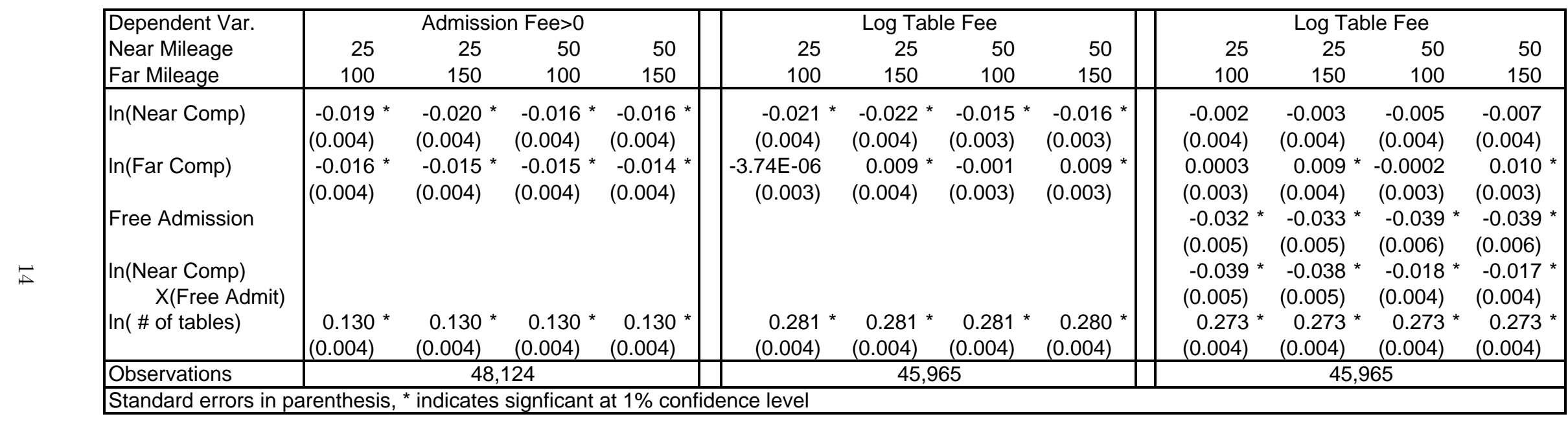

Notes: All columns use linear models with fixed effects for location (3 digit zip codes), time (monthly) and days-of-the-week that the convention covers). Near competition is the number of conventions with the "Near Mileage" number that overlap in the calendar. Far competition uses the "Far Mileage" number, and is not inclusive fo near competition. We add 1 to each number to address log zeros. 
We also study whether conventions constrained that allow free admission to consumers set dealer prices differently in response to competition than conventions that charge admissions. For these purposes, we additionally project dealer price onto a dummy variable for whether the convention offers free admission, and importantly, the interaction of the dummy with the log of nearby competition. We interpret conventions that allow free admission to be price-constrained. Presumably these conventions would not reduce their fee in response to small changes in exogenous variables. There is a sense in which every convention is constrained as they tend to use round numbers for the admission fee so it does not appear to be a truly continuous choice variable. However, we view the conventions with free admission as the "most constrained" conventions: they would be least likely to adjust their admission fee in response to changes in market variables. In theory, conventions could use raffle tickets or door prizes to implement a sort of negative price, but these should be inefficient instruments to pay consumers relative to actual price, so we still view conventions with free admission as price constrained. We discuss the theoretical treatment of price constraints in the next section, but as we argue, the theoretical models do not depend on competition affecting one side more than the other, which is why we focus the interaction term on "near" competition, which affects both sides of the market.

Results appear in the third panel of Table 7. In these columns, the coefficient on nearby competition becomes insignificant and precisely estimated near zero. Instead, we see a negative and significant coefficient on the interaction term, with a substantially higher magnitude than we found on nearby competition in panel 2. That is, the negative effect of nearby competition that we observed earlier appears to be coming from the constrained firms. Thus, constrained firms respond more strongly to competition than unconstrained firms. ${ }^{11}$ As before, we see no effect of far competition when measured at 100 miles and a positive and significant effect at 150 miles.

These set of results motivate us to try a final, more ambitious regression that captures our "entire story" in a single regression. We predict table fees with separate variables to control for near competition (less than 50 miles), far competition (50-100 miles), very far competition (100-250 miles) and out-of-range competition (250-400 miles). We also interact near competition with a dummy for free admission. Results for the table fee appear in Column 1 of Table 8. Results are largely consistent with our earlier findings. We find no effect of competition more than 250 miles away, which we interpret as being too far to be in the relevant market. We find a positive effect on competition for the 100-250 mile range, and we find competition has no effect on dealer prices in the 50-100 mile range. We find a negative effect in the nearby range (less than 50 miles) for conventions that do not charge admission. Unlike in the previous regression, we find that competition within 50 miles has a negative effect even for conventions that charge admission.

For our story to be complete, we should also find that the effect of competition on admission fees is negative over the $0-250$ mile range and zero outside of that range. Column 2 of Table 8 estimates

\footnotetext{
${ }^{11}$ Note that both admission and table fees are determined simultaneously so there is a potential endogeneity problem with including admission fees on the right-hand side. We discuss this further below.
} 


\begin{tabular}{|c|c|c|c|}
\hline & $\begin{array}{l}\text { Table } \\
\text { Fee }\end{array}$ & $\begin{array}{l}\text { Admission } \\
\text { Fee }\end{array}$ & $\begin{array}{l}\text { Admission } \\
\text { Fee }\end{array}$ \\
\hline free admit & $\begin{array}{l}-0.025^{*} \\
(0.006)\end{array}$ & & \\
\hline$<50$ & $\begin{array}{r}-0.004 \\
(0.004)\end{array}$ & $\begin{array}{l}-0.014 * \\
(0.004)\end{array}$ & $\begin{array}{l}-0.018 * \\
(0.004)\end{array}$ \\
\hline$<50 *$ free & $\begin{array}{l}-0.020 * \\
(0.004)\end{array}$ & & \\
\hline $50-100$ & $\begin{array}{r}-0.0003 \\
(0.004)\end{array}$ & $\begin{array}{l}-0.011 * \\
(0.004)\end{array}$ & $\begin{array}{l}-0.013 * \\
(0.005)\end{array}$ \\
\hline $100-250$ & $\begin{array}{r}0.021 * \\
(0.004)\end{array}$ & $\begin{array}{r}-0.004 \\
(0.004)\end{array}$ & \\
\hline $250-400$ & $\begin{array}{r}0.003 \\
(0.004)\end{array}$ & $\begin{array}{l}0.020 * \\
(0.005)\end{array}$ & $\begin{array}{r}0.008 \\
(0.005)\end{array}$ \\
\hline \multicolumn{4}{|c|}{$\begin{array}{l}\text { Standard errors in parenthesis } \\
* \text { indicates signficant at } 1 \% \text { confidence level }\end{array}$} \\
\hline \multicolumn{4}{|c|}{$\begin{array}{l}\text { Note: The first two columns reestimate column } 3 \text { of panels } 1 \\
\text { and } 3 \text { of Table } 7 \text {, but with four competition distances } \\
\text { instead of two. The third column re-estimates column } 2 \\
\text { with the restriction that the parameters on } 50-100 \text { and } 100 \text { - } \\
250 \text { are the same. }\end{array}$} \\
\hline
\end{tabular}

Table 8: Results with four competition distances

the linear probability model on admission fee with the same four competition variables as we used for the table fee. We find significantly negative coefficients for 0-50 and 50-100. However, we we find a zero coefficient for 100-250 and positive coefficient for the 250-400 range. We prefer the specification in Column 3, in which we restrict the model to have the same coefficient for 50-100 and 100-250. In this case, we find the expected results of negative coefficients on 0-250 and zero for 250-400.

Note that all results in Tables 6, 7 and 8 are robust to using standard errors that are clustered at the level of the location-month. The one exception is the surprising positive coefficient on the 250400 range in Column 2 in Table 8. Under clustering, this coefficient is not significantly different from zero, which conforms to our expectations for this coefficient. One issue that clustering addresses is that location-months with many conventions count more in the regression results. Also, all results on sign and significance in the admission fee regressions are robust to switching to Chamberlain's conditional logit model.

\section{Interpretation}

The previous section establishes a set of stylized facts drawn from a two-sided market. We find that competition at any relevant distance decreases consumer admission prices. However, prices for dealers are more complex. In this section, we argue that set of results is consistent with the theory of two-sided markets. These theories are very flexible and perhaps could generate a variety of results. However, we 
argue that the set of assumptions that generate our results are natural for this market.

Among the most widely accepted implications of the theoretical literature on competition in twosided markets is that competition between platforms affects the side that single-homes much more than the side that multi-homes. For instance, this result appears in Armstrong (2006), Rochet \& Tirole (2003), and Gomes (2011). Assuming that dealers are more likely to multi-home than consumers, that implies that competition affects consumer prices more than dealer prices. Intuitively, the only way for dealers to reach consumers is through the convention that the consumer chooses. Hence, the convention has monopoly power over the dealer for access to its consumers. This makes competition to attract consumers particularly intense. There is no competition to attract dealers, since multihoming implies that the decision of dealers is separable across conventions. Thus, an increase in competition among conventions (for instance, by exogenously moving conventions closer together or by adding one to the market) creates lower prices for consumers but much less so, or not at all for dealers. ${ }^{12}$

Interestingly, Armstrong (2006) provides a similar result in the case in which both consumers and dealers single-home. In that case, increasing competition on one side of the market but not the other lowers prices on that side, but does not affect prices on the other. ${ }^{13}$ However, this result is driven by the assumption that both sides of the market are fully served by the conventions. Thus, there is no market-expansion effect to lower prices.

To capture a more realistic case in which some agents choose not to attend either convention, we present a formal theoretical model in the appendix. In our model, consumers and dealers are distributed uniformly on separate "Hotelling" lines. Two conventions have separate locations on each line. The conventions are not at the end points of the lines. Rather, the lines extend far enough past the conventions in both directions that there is always a market expansion effect to lower prices. Conventions choose fees simultaneously, separately setting both a consumer and dealer admission fee. Then, consumers and dealers simultaneously decide which convention to attend, accounting for their travel costs, the fees, and the number of agents on the other side. We consider parameters such that in equilibrium, agents between the conventions are fully served whereas some agents on the sides choose not to participate. Thus, our model extends Armstrong (2006) to allow for a market expansion effect. While the model does not generate easily interpretable equations, numeric solutions replicate all of the theoretical results that we discuss for both single-homing and multi-homing dealers.

Our presentation in the appendix focuses on the case in which single-homing consumers and dealers since this generates a striking result does not appear in the preceding theoretical literature: An increase

\footnotetext{
${ }^{12}$ Existing theoretical work on platform competition considers cases with only two conventions, and studies changes in competition by varying the distance between them. Naturally, our empirical specification is designed to handle much more varied market structures. We interpret an increase in the number of competing conventions as the theoretical equivalent of moving a platform from a really far distance that has a minimal competitive effect (say more than 300 miles away) to a distance that counts for near or far competition.

${ }^{13}$ For example, see Equation 12 in Armstrong (2006).
} 
in competition for consumers leads to lower prices for consumers and higher prices for dealers. Intuitively, as competition increases for consumers, the number of consumers served decreases for each convention. Since part of the value of attracting dealers is that it allows the convention to raise price to consumers, dealers become less valuable as the number of consumers goes down. The decreased marginal benefit of attracting a dealer causes the conventions to raise the price to dealers. This effect was masked in the model of Armstrong, which assumed that quantity stayed constant on both sides (via the "fully served" assumption). ${ }^{14}$ In our model, the only difference between consumers and dealers is that consumers have higher travel costs.

Thus, our basic empirical result that competition causes prices to fall for consumers but to remain unchanged or increase for dealers can be rationalized by the theory of two-sided markets. In fact, we can say more. Competition does not affect dealer prices in a model in which dealers multi-home and competition causes prices to increase in a model in which dealers single-home. Thus, our empirical result that competition between conventions less than 100 miles apart has no effect on dealer price and competition greater than 100 miles away causes dealer prices to increase is consistent with a model in which dealers multi-home between conventions at lower distances but single-home at greater distances.

We have no direct data on the extent to which dealers single-home or multi-home. Presumably, there is a mix of each. It is difficult to say when multi-homing is more prevalent. Certainly, it seems natural to think that dealers would be more likely to split their collection among two conventions when the conventions are not very far apart. Furthermore, our interviews with industry participants were suggestive of our interpretation. They confirm that dealers travel further than consumers, and generally treat travel as less important. Furthermore, dealers are capable of splitting their collection. One example where this might come up would be if a dealer regularly appeared at a monthly card show that happened to overlap with a very large annual show. Without further data, which we do not believe is available, we cannot further explore this issue, so we simply note that our interpretation of the empirical results is consistent with a reasonable description of market behavior.

To be clear, there are no theoretical models we know of that endogenize the change from single-homing to multi-homing - it is always imposed by the model. However, it is straightforward to think about how this might work. Recall that most dealers are very small businesses. Multi-homing probably means that the dealer attends one convention and hires an employee or family member to attend another. Whereas the dealer may regard his own travel costs as very low, paying an employee for time and car usage may make distant conventions more costly. Alternatively, a dealer may hire employees to go to both conventions (perhaps for only part of the day) and then the dealer would visit both conventions himself as well. In either case, we could imagine increasing the distance between conventions endogenously switching

\footnotetext{
${ }^{14}$ One can see our result in the model of Weyl (2010), which only models the monopoly case but with more general demand functions than we have here. Weyl shows that the equilibrium price to one side depends on the number of agents on the other side (see equation 4). If the quantity on the other side goes down, for instance because of competition, so does the price.
} 
the dealer's preferences from a multi-homing model, where the dealer's decision at each convention is independent of the other, to a single-homing model, where the dealer must choose which one of a set of conventions to attend.

Recall that in Table 8, we found that price responded negatively to competition within 50 miles even for conventions that charged for admission. This result is not consistent with our story in which dealers purely multi-home, consumers single-home and agents never substitute between being consumers and dealers, which would predict no effect of competition on dealer price. However, we do not view this as particularly troubling. First, we did obtain the result of no significant effect in Table 7, so this problematic result is not entirely robust. Furthermore, it seems reasonable that at close distance, onesided logic is more powerful than two-sided logic, and leads prices to fall in competition. Perhaps some dealers substitute to enter as consumers, or some consumers multi-home at short distances, which could explain this outcome formally.

An additional empirical result is that competition affects price-constrained platforms differently. Armstrong \& Wright (2007) study how a constraint on one side affects pricing on the other. Writing in terms of the sports card application, they show that conventions that choose free admission reduce dealer prices in response to increases in competition more strongly than do conventions that use positive admission fees. Intuitively, competition induces firms to set lower consumer fees. When consumer fees reach zero, conventions must find another method to attract consumers as competition increases, and so conventions turn towards attracting dealers. Thus, pricing to dealers is more aggressive in competition when consumer prices are constrained. ${ }^{15}$

Gomes (2011) also finds that competition has a bigger effect on seller prices when the platform cannot price to consumers, with similar intuition. His approach is notable because he uses a mechanism design approach, and so in this sense considers very general pricing functions. ${ }^{16}$

A potential issue in the empirical model is that admissions and dealer prices are set simultaneously. However, the theoretical relationship between the two prices can be interpreted as an equilibrium correlation rather than a causal effect. That is, in Armstrong \& Wright (2007), competition is the exogenous variable. As competition increases, consumer prices drop until they hit their boundary, at which point dealer prices fall. Thus, our regressions are consistent with the theory in this sense. There may still be

\footnotetext{
${ }^{15}$ Armstrong \& Wright (2007) make this point in the context of their model in which agents are fully served by conventions. We have confirmed these predictions in our model which allows for a market expansion effect. Also, they generate asymmetry by allowing the "network effect" parameters (what we label $\alpha$ in the appendix) to differ across consumers and dealers. We have confirmed these results allowing for heterogeneity in the other parameters, such as the travel cost $(t)$ and stand-alone utility $(v)$. We also have checked these results when dealers single-home and multi-home. Results are available on request.

${ }^{16}$ Gomes (2011) is motivated by Internet search auctions but the model is still relevant for our context. In considering implementation, Gomes focuses on a platform that auctions access to users. In his model, the platform sets the weight it will put on the seller's bid relative to the quality the seller will provide to the consumers. While Gomes does not study price explicitly, raising the weight on the bid causes sellers to bid more aggressively, which is analogous to raising price in our setting. He finds that the auction is not affected by competition between platforms when the platform can subsidize consumers, but that the weight on the bid goes down in competition when pricing to consumers is constrained.
} 
more standard empirical problems to worry about. For instance, unobserved location heterogeneity could lead to low consumer and dealer prices and high competition, which would generate our empirical result. We find this possibility unlikely - standard intuition suggests that unobserved heterogeneity generates a positive correlation between prices and entry, not negative.

Overall, theory provides a consistent interpretation of our regression results. Dealers multi-home and so competition between conventions has no effect on dealer prices over some middle range. When conventions are very close, admission fees are driven to zero and then conventions compete by lowering dealer fees. When conventions are far from each other, dealers switch to single-homing, in which case dealer prices increase in competition, since competition for consumers is more intense than competition for dealers.

Clearly, we have not established that the theory of two-sided markets is the only theory that could generate these results, but we believe that it is difficult to find an alternative, particularly for the result about increased prices. There are a variety of ways that someone might model this market but without specifying an explicit model, it is surely true that most multi-product oligopoly models predict that prices fall in competition, rather than increase. Our empirics do not provide a test of two-sided market theories in the sense of developing falsifiable predictions from the theory of two-sided markets. Rather, our goal is to provide a set of stylized facts from the industry and argue that they can be rationalized with these theories.

A theory that generates prices that increase in competition exists for prescription drugs, in which we have seen brand-name drugs raise prices after entry by a generic drug (for instance, see Ching, 2010). These models rely on the entrant successfully capturing the high elasticity customers, leaving the incumbent to exploit the remaining low elasticity customers, where elasticity is driven by the type of insurance that a consumer has. That kind of differentiation between platforms and heterogeneity in elasticity seems unlikely to be relevant for the card convention market.

\section{Conclusion}

We provide a set of empirical results drawn from a new data set on sports card conventions in the U.S. in the mid-1990s. These conventions are a two-sided market since convention organizers must set admission and table fees to attract consumers and dealers. This setting is compelling for the study of two-sided markets because we observe many, many conventions and thus variation in market structure, and the pricing setting is simple and easily interpretable.

We show that consumer prices respond to the number of conventions both nearby and far. In contrast, dealer prices at conventions within 100 miles do not respond to competition between conventions, except for a negative effect for conventions that do not charge admission. Also, competition that is more than 100 miles away (when dealer single-homing is likely) causes prices to increase. We argue that this set of 
results is consistent with the existing theories of two-sided markets. Thus, we find that empirical evidence from the sports cards market supports the recent theoretical literature on two-sided markets. Existing theoretical work considers no more than two competing conventions, whereas our empirical setting is much more varied. Therefore, our results suggest that intuition obtained in a duopoly market structure can be extended to more complicated market structures. 


\section{References}

Ackerberg, D. A. \& Gowrisankaran, G. (2006). Quantifying equilibrium network externalities in the ach banking industry. RAND Journal of Economics, 37, 738-761.

Argentesi, E. \& Filistrucchi, L. (2007). Estimating market power in a two-sided market: The case of newspapers. Journal of Applied Econometrics, 22, 1247-1266.

Armstrong, M. (2006). Competition in two-sided markets. RAND Journal of Economics, 37, 668-691.

Armstrong, M. \& Wright, J. (2007). Two-sided markets, competitive bottlenecks and exclusive contracts. Economic Theory, 32, 353-380.

Caillaud, B. \& Jullien, B. (2003). Chicken \& egg: Competition among intermediation service providers. RAND Journal of Economics, 34, 309-328.

Cantillon, E. \& Yin, P.-L. (2008). Competition between exchanges: Lessons from the battle of the bund. Unpublished Manuscript, Sloan School of Management, Massachusetts Institute of Technology.

Chamberlain, G. (1980). Analysis of covariance with qualitative data. Review of Economic Studies, 47, 225-238.

Chandra, A. \& Collard-Wexler, A. (2009). Mergers in two-sided markets: An application to the canadian newspaper industry. Journal of Economics and Management Science, 18, 1045-1070.

Ching, A. (2010). A dynamic oligopoly structural model for the prescription drug market after patent expiration. International Economic Review, 51, 1175-1207.

Corts, K. S. \& Lederman, M. (2009). Software exclusivity and the scope of indirect network effects in the u.s. home video game market. International Journal of Industrial Organization, 27, 121-136.

Derdenger, T. (2011). Technological tying and the intensity of competition: Empirical analysis of the video game industry. Unpublished Manuscript, Tepper School of Business, Carnegie Mellon University.

Fan, Y. (2011). Ownership consolidation and product characteristics: A study of the U.S. daily newspaper market. Unpublished Manuscript, University of Michigan.

Farrell, J. \& Klemperer, P. (2007). Handbook of Industrial Organization, Vol 3, chapter Coordination and Lock-In: Competition with Switching Costs and Network Effects. Elsevier.

Gandal, N., Kende, M., \& Rob, R. (2000). The dynamics of technological adoption in hardware/software systems: The case of compact disc players. RAND Journal of Economics, 31, 43-61.

Genakos, C. \& Valletti, T. (2011). Testing the waterbed effect in mobile telecommunications. Journal of the European Economic Association, 9, 1114-1142.

Goldmanis, M., Hortascu, A., Syverson, C., \& Emre, O. (2010). E-commerce and the market structure of retail industries. Economic Journal, 120, 651682.

Gomes, R. (2011). Optimal auction design in a two-sided market. Unpublished Manuscript, Toulouse School of Economics.

Hagiu, A. \& Wright, J. (2011). Multi-sided platforms. Unpublished Manuscript, Harvard Business School.

Jeziorski, P. (2011). Estimation of cost synergies from mergers without cost data: Application to U.S. radio. Unpublished Manuscript, Haas School of Business. 
Jin, G. Z. \& Kato, A. (2007). Dividing online and offline: A case study. Review of Economic Studies, 74, 981-1004.

Kaiser, U. \& Wright, J. (2006). Price structure in two-sided markets: Evidence from the magazine industry. International Journal of Industrial Organization, 24, 1-28.

Lee, R. (2010). Dynamic demand estimation in platform and two-sided markets. Unpublished Manuscript, Stern School of Business.

Rochet, J.-C. \& Tirole, J. (2003). Platform competition in two-sided markets. Journal of the European Economic Association, 1, 990-1029.

Rochet, J.-C. \& Tirole, J. (2006). Two-sided markets: A progress report. RAND Journal of Economics, 37, 645-667.

Rysman, M. (2004). Competition between networks: A study of the market for yellow pages. Review of Economic Studies, $71(2), 483-512$.

Rysman, M. (2007). Empirical analysis of payment card usage. Journal of Industrial Economics, 60, 1-36.

Rysman, M. (2009). The economics of two-sided markets. Journal of Economic Perspectives, 23, $125-144$.

Saloner, G. \& Shepard, A. (1995). Adoption of technologies with network effects: An empirical examination of the adoption of Automated Teller Machines. RAND Journal of Economics, 26, 479-501.

Weyl, E. G. (2010). A price theory of multi-sided platforms. American Economic Review, 100, 1642-1672.

Wright, J. (2010). Why do merchants accept payment cards? Review of Network Economics, 9, Article 1. 


\section{A Appendix: An illustrative model of sports card conventions}

Competition among sports card conventions can be summarized as the number of competitors that a convention faces in the same time frame within a specific distance. However solving a theoretical model that allows for variation in both the number of platforms and distance between platforms is a challenge. Like the existing theoretical literature on two-sided markets, we restrict our model to have two platforms and and we use the distance between platforms to proxy for the level competition. In Section 4 , we explain how we interpret predictions from this model in the context of sports card conventions. See footnote 12 as well.

We base our work closely on the model of Armstrong (2006). This model is useful for representing the sports card convention market because it address competition between two platforms that charge only a fixed fee to each agent and do not charge based on the number of trades made through the platform. We extend this model to allow for a market expansion effect from lowering prices. While doing so complicates the model, it also provides more realistic results to take to data.

Consider two sides of a market, with one set of agents on each side. Side $C$ is made up of consumers and side $D$ is make up of dealers. We index sides by $m$. Consumers and dealers are distributed along separate real number lines with density one. They are distributed across the entire line. ${ }^{17}$ Agent $i$ in market $m$ is located at $l_{i}$ (we do not index $l_{i}$ by market for notational convenience). Consumer $i$ bears no relationship with dealer $i$ in side D. That is, they make their choices independently. There are two conventions, or "platforms", 1 and 2 , indexed by $j$. Throughout, we assume that platforms have no costs. The platforms sell to consumers and dealers simultaneously. The location of platform $j$ in side $m$ is $l_{j}^{m}$. In this set-up, we can consider comparative static in $l_{j}^{C}$ but not $l_{j}^{D}$, as if a platform could change its location with respect to consumers but not dealers. Clearly, this is an abstraction since an actual change in geographic location would affect all types of agents, but we think of this is an approximation to a situation in which one set of agents cares about location much more than the other. Alternatively, one may assume conventions have the same location on each side of the market (that is, $l_{j}^{C}=l_{j}^{D}$ ) but with consumers having higher travel costs than dealers $\left(t^{C}>t^{D}\right)$. We solve this alternative model and find the same qualitative results, although the equations are much more complicated and we must resort to numerical analysis to a greater degree. For this reason, we only present the model that assumes equal travel cost but allows platforms to change locations on the two sides asymmetrically.

Agents value a platform based on how many agents the platform serves in the other side. Suppose platform $j$ sells to $n_{j}^{C}$ consumers and $n_{j}^{D}$ dealers. The utility to agent $i$ in side $m$ is $u_{i j}^{m}$, defined to be:

$$
\begin{aligned}
& u_{i j}^{C}=v+\alpha n_{j}^{D}-p_{j}^{C}-t\left|l_{i}-l_{j}^{C}\right| \\
& u_{i j}^{D}=v+\alpha n_{j}^{C}-p_{j}^{D}-t\left|l_{i}-l_{j}^{D}\right|
\end{aligned}
$$

where $v$ represents the stand-alone utility of purchase to consumers and dealers, $\alpha$ determines the value conferred by sales in the other side of the market, $p_{j}^{m}$ is the price of platform $j$ in side $m$, and $t$ parameterizes the travel cost. We assume that agents could instead use some outside good with utility of zero. Figure 3 displays our model visually.

Note that we are treating dealers symmetrically with consumers. We do not model price-setting, competition or other externalities between dealers. Doing so would complicate our analysis unnecessarily. Wright (2010) presents a model with within-group competition that turns out to be just a change of

\footnotetext{
${ }^{17}$ The important assumption is not that agents extend forever across each line but that they extend past whatever location would generate sales for zero prices, so there is always a demand expansion effect to lower prices.
} 


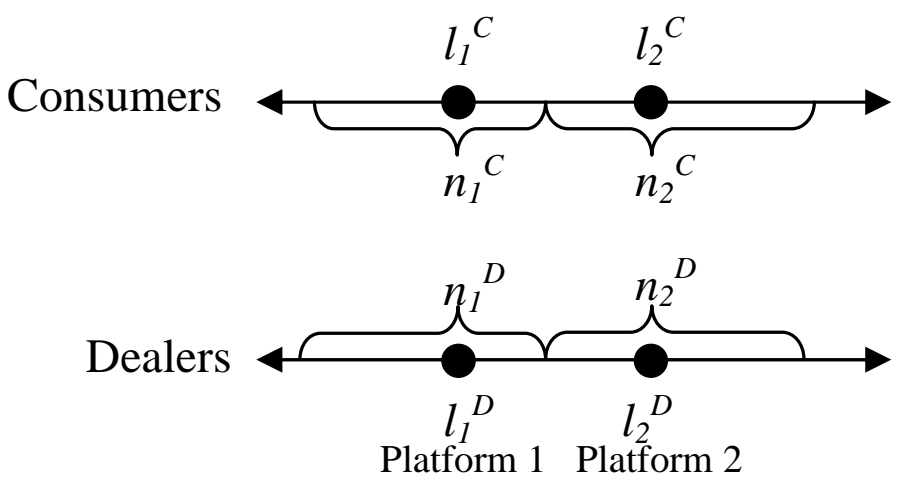

Figure 3: Consumers, dealers, platform locations and quantities.

variables from the model we consider. Also, we assume there is agent heterogeneity in $l_{i}$ but not $\alpha$. Weyl (2010) explores a model with heterogeneity in both terms but we have not done so as we believe that geographic heterogeneity is the most important issue in our application.

Throughout, we parameterize the model as follows, which we regard as without loss of generality:

$$
\text { Assumption } 1 \quad l_{1}^{C}=-1 \quad l_{1}^{D}=-1 \quad l_{2}^{D}=1 \quad t=1 .
$$

We want to consider comparative statics of prices in $l_{2}^{C}$. An alternative would be to allow $t$ to be heterogeneous across markets and consider comparative statics in consumer $t$. However, note that reductions in $t$ bring conventions closer together and increase the responsiveness to the number of agents on the other side, like increasing $\alpha$. We wish to isolate the competitive effect, and so focus on $l_{2}^{C}$.

We assume that the two platforms choose prices simultaneously and we solve for a Nash equilibrium of the game. Platforms are symmetric and we find only symmetric equilibria. Hence, we always find that $P_{1}^{m}=P_{2}^{m}$ for $m=\{C, D\}$.

We consider the case in which consumers and dealers both single-home. That is, agents pick the single platform that gives the highest utility, or choose no platform if the value of purchase does not exceed their reservation value of zero.

We are interested in cases in which there is a strategic interaction between the two platforms, so we consider cases in which all consumers located between the two platforms prefer purchasing from either platform to no purchase. Armstrong (2006) obtains simple analytic solutions to a similar model in which agents are assumed to be on finite lines and platforms are at the ends of these lines. However, the lack of a demand expansion effect leads to some unrealistic implications. The principal innovation of our model is to incorporate a demand expansion effect by allowing agents to be located on both sides of the platforms. While our solutions are less elegant, they are more relevant for our empirical work. is:

For each platform, profit is $\pi_{j}=p_{j}^{C} n_{j}^{C}+p_{j}^{D} n_{j}^{D}$. Demand for each platform on each side of the market

$$
n_{j}^{m}=\frac{\left(\alpha n_{j}^{-m}-p_{j}^{m}\right)-\left(\alpha n_{-j}^{-m}-p_{-j}^{m}\right)}{2}+\frac{l_{2}^{m}-l_{1}^{m}}{2}+v+\alpha n_{j}^{-m}-p_{j}^{m}
$$

where $n_{-j}^{-m}$ refers to the number of agents purchasing the other platform's product in the other side. The first two terms refer to the profit drawn from agents between the two platforms. The first term will be 
zero in a symmetric equilibrium and the second term increases as the platforms become farther apart. The last term captures the profits drawn from agents on the other sides of the platforms.

We take first-order conditions from the profit functions for each price and we solve for prices by solving the four first-order conditions simultaneously. ${ }^{18}$ Algebraic manipulation shows that:

$$
\frac{d p_{1}^{D}}{d l_{2}^{C}}<0 \quad \text { if } \quad 0<\alpha<\frac{5}{8}
$$

This result implies that $p_{1}^{D}$ decreases as platform 2 becomes farther away on side $C$, if the network effect is not too large. ${ }^{19}$ That is, higher competition on one side increases prices in the other. We consider the finding that prices increase in competition to be very surprising. It would be difficult to replicate in a model with only single-sided interaction.

The condition that the network effect be not too large turns out to be non-binding. As is well-known in the network effects literature, large network effects lead to intense price competition. There exists a critical value of $\alpha$ such that prices become zero. It takes on a particularly simple form in our model: when $l_{2}^{C}=1$, prices are greater than zero if $\alpha<1 / 2$. Obviously, this lies below $5 / 8$. Hence, we would never consider values of $\alpha$ such that $d p_{1}^{D} / d l_{2}^{C}>0$.

To get a sense of the whole set of prices, consider the specification with $v=1$ and $\alpha=0.3$. These parameters imply that for $l_{2}^{C}=1$, all consumers and dealers between the platforms purchase. Then, prices are:

$$
\begin{array}{ll}
p_{1}^{C}=0.27+0.19 l_{2}^{C} & p_{1}^{D}=0.49-0.03 l_{2}^{C} \\
p_{2}^{C}=0.27+0.19 l_{2}^{C} & p_{2}^{D}=0.49-0.03 l_{2}^{C}
\end{array}
$$

Not surprisingly, platform 1 increases its price to consumers as platform 2 becomes farther away on that side. However, we also see that platform 1 decreases its price to dealers as platform 2 becomes farther away on the consumer side.

What is the intuition for this surprising result? As platforms become closer together, they serve fewer consumers. Thus dealers, who are attractive in part because they allow the platform to raise price on consumers, are less attractive. Hence, platforms raise price to dealers. Note that this result is unique to our setting because we have a demand expansion effect. Armstrong (2006) finds that changing the distance between platforms on one side does not affect prices on the other. This follows from Armstrong's assumption that consumers are fully served.

As noted in footnote 15, we have also solved versions of our model when assuming that dealers can multi-home, and when $v, \alpha$ or $t$ differ for consumers and dealers, inducing platforms to set a price of zero to one side. As these results are consistent with existing theory, we do not present them here, although they are available upon request.

\footnotetext{
${ }^{18}$ All derivations in this paper are available in Mathematica files and PDF output on our web site, at http://people.bu.edu/mrysman/research/.

${ }^{19}$ It turns out that this condition also implies that all agents between the two platforms are served as long as $v$ is high enough, in particular $v>7 / 6$. For lower values of $v$, we require $\alpha$ to be above some low value, but this requirement could be eliminated by lowering $t$.
} 